NASA Technical Memorandum 104423

AIAA-91-2463

\title{
Fuel-Rich, Catalytic Reaction Experimental Results
}

R. James Rollbuhler

Lewis Research Center

Cleveland, Ohio

Prepared for the

27th Joint Propulsion Conference

cosponsored by the AIAA, SAE, ASME, and ASEE

Sacramento, California, June 24-27, 1991 
FUEL-RICH, CATALYTIC REACTION EXPERIMENTAL RESULTS

\author{
Jim Rollbuhler \\ National Aeronautics and Space Administration \\ Lewis Research Center \\ Cleveland, Ohio 44135
}

\title{
SUMMARY
}

An experimental investigation has been conducted involving the partial oxidation reaction of a fuel-rich gaseous mixture of fuel and air in a catalyst containing reactor. The fuel used was Jet-A and it was vaporized in a hot air stream before being introduced into the catalytic reactor. There was limited air in the mixture, the fuel to air equivalence ratio was 3.5 to 7.5 , so that only a partial breakdown and oxidation reaction of the fuel could occur. The reactor discharge gases were at a maximum temperature of about $1375 \mathrm{~K}$ and contained high concentrations of hydrogen ( 5 to 10 vol \%), carbon monoxide (10 to $15 \mathrm{vol} \%$ ), and light and heavy end hydrocarbons. The nitrogen oxide concentration was very low, possibly because of hydrogen reduction. Various ceramic catalyst mounting techniques were developed to maintain physical integrity of the monolith pieces over the sequence of test cycles.

\section{INTRODUCTION}

A key issue in the development of the next generation high-speed civil transport is environmental acceptability. Of particular concern is that the nitrogen oxide $\left(\mathrm{NO}_{\mathrm{x}}\right)$ emissions, from the aircraft gas turbine engines operating at high altitudes do not have detrimental effects on the Earth shielding stratospheric ozone layer. This concern has led to significant development efforts in atmospheric modeling, combustion analysis, and testing of various combustor concepts that favor low $\mathrm{NO}_{\mathrm{x}}$ combustion.

A concept of interest is staged combustion. A simplified explanation of this is to have two distinct reaction regions in a combustor, one to initiate a fuel-air reaction and a second to complete the combustion process. The goal is to achieve the overall process with only minimum reaction occurring at stoichiometric conditions where the maximum concentration of No would be formed. This is shown in figure 1, which is a generalized plot of reaction temperature and $\mathrm{NO}$ concentration as a function of the fuel to air or equivalence ratio (ER). ${ }^{x}$ Ideally, the fuel and input air begin reacting in a fuel-rich concentration, i.e., to the right of the fuel-air stoichiometric concentration point in figure 1. Because of insufficient combustion air at the fuel-rich ER, the vaporized fuel will only partially react. The partially oxidized fuel-air mixture is then quickly mixed with additional air such that a fuel-lean concentration condition results, at which condition the combustion of the fuel is carried to completion. The key factor is quick and complete mixing of the partially reacted fuel-air mixture with more air so that there is not enough dwell time for stoichiometric combustion to occur.

The program described in this report concerns the first stage reaction mechanisms required to vaporize and partially react a liquid hydrocarbon fuel (i.e., Jet-A) with hot incoming combustion air. The technique used to bring about the partial reaction was exposure of the fuel-air mix to a catalyst. The catalyst will initiate a controlled reaction at low threshold temperatures 
and in theory it has an unlimited life. Previous work involving partial oxidation using catalysts here at NASA Lewis Research Center is reported in reference 1 .

This program tested a number of different catalyst types and material configurations. This report details efforts using ceramic, monolith, substrate material that has been commercially coated with platinum or palladium active compounds. Steady-state testing was done with these catalysts over a range of combustion air flows, incoming air temperatures, and fuel to air ratios (ER); all in a flame tube type test reactor. Detailed diagnostic measurements were made of the overall catalyst reactor performance, including the product discharge gas composition and changing gas temperatures.

In the near future the results of this program will be incorporated into a two stage combustor to be tested here at NASA Lewis.

\section{TEST FACILITY}

This program was carried out in the combustion research laboratory, cell 23, at NASA Lewis. A schematic of the test facility is shown in figure 2 .

In order to simulate compressor or ram combustion air coming into a combustor at high temperatures, the rig input air was passed through a counter-flow, high temperature heat exchanger. The exchanger was designed to heat up to $1.0 \mathrm{~kg} / \mathrm{sec}$ of air to a maximum temperature of $1250 \mathrm{~K}$. This is accomplished with a single pass of the air through a slowly rotating, porous ceramic wheel. As the wheel rotates, it passes through a burner exhaust gas stream in an adjoining chamber separated from the air flow passage chamber by gas seals on the rotating wheel surfaces. The portion of the wheel heated in the exhaust gas stream proceeds to rotate into the air passage chamber where the flow-through air removes the wheel heat as the wheel again enters the hot exhaust gas chamber. By varying the hot exhaust gas temperature and/or the wheel rotation speed, different air flow rates can be heated to different temperatures.

The rig test section is immediately downstream of the heat exchanger hot combustor air outlet. The liquid test fuel is injected into the hot air stream using a fuel-air multi-orifice atomizing injector unit. The introduced fuel was at ambient temperature and its flowrate was determined by the fuel pump output pressure selected.

The fuel-air mixture then flowed through the instrumented test reactor and was then cooled and discharged from the system. Since this program was only interested in investigating the first-stage, fuel-rich reaction process, the product gases were vented to the atmosphere. Because the gases contained high concentrations of hydrocarbons, hydrogen, and carbon monoxide they were completely combusted in a flare burner at the end of the vent stack. Tests of the atmosphere downwind of the discharge stack did not indicate any measurable level of pollution. 
The test section used in this program consist of a number of internally insulated stainless steel pipe sections bolted together in series. Easy buildup and teardown of the pieces simplified the installation of catalyst pieces and post-test inspection of the internal components. The test section is shown schematically in figure 3 .

The hot combustion air, flowing out of the facility heat exchanger, enters the test section at the upper left in figure 3 . The air then flows through a 19 port, air blast, nozzle unit where the liquid hydrocarbon test fuel is introduced. The air flowrate has been set at a value between 0.2 and $0.5 \mathrm{~kg} / \mathrm{sec}$ and is at a temperature of approximately 820, 930, or $1050 \mathrm{~K}$. The fuel is sprayed through $1 \mathrm{~mm}$ orifices, one at each of the 19 ports in the nozzle unit. The fuel flowrate is varied in discrete quantities between 0.03 and $0.30 \mathrm{~kg} / \mathrm{sec}$ to obtain the desired test fuel to air ratio. Each of the fuel injection orifices is surrounded by a space through which cooling air is injected to prevent the fuel from carbonizing in the orifice passages. This is a concern because the entire nozzle unit is being heated by the combustion air flow up to $1050 \mathrm{~K}$. The cooling air flow is about $25 \mathrm{~g} / \mathrm{sec}$ and this quantity is included in the overall air mass being used to calculate the ER. The fuel may enter the nozzle unit as a liquid but at injection into the hot air, its state is a function of the heat transfer from the hot air to the nozzle mass to the fuel stream. The fuel pressure drop is monitored as a function of flow rate to determine if passage blockage is occurring and during this program this did not occur.

After the fuel and air mix in the nozzle unit, there is a residence volume about three pipe diameters long before the gas mixture enters the catalytic reactor section. In this residence volume the fuel droplets have a chance to absorb heat from the air and vaporize. The residence or dwell time in the vaporization section is 12 to $19 \mathrm{msec}$ depending on the mass flowrate. By measuring the temperature drop of the fuel-air mixture in this volume, it is possible to determine the extent of fuel vaporization and subsequent heatup. The temperatures are measured at several locations in this residence volume using shielded thermocouple rakes.

The catalyst reaction portion of the test section can accommodate up to about $25 \mathrm{~cm}$ of $15 \mathrm{~cm}$ diameter catalyst material. The material has been in the form of monolithic ceramic or metallic discs which are between 25 and $75 \mathrm{~mm}$ in thickness. The discs look like honeycomb material with from 4 to 100 axial flow-through passages per square centimeter of disc face surface. When the reaction section was made with discs with space between them, thermocouples were inserted into the void gas space.

After the reactor section, about two pipe diameters further downstream, is a cross-sectional area containing 12 thermocouples and a gas sampling probe. The thermocouples are equally spaced around the circumference for determining the reactor product gas temperature pattern.

Downstream of the thermocouple/gas sample probe area, are two observation windows on either side of the exhaust gas duct. A video camera televises the gas flow and a digital temperature meter visible through the opposite window. The temperature reading is that of the gases flowing by the windows. The view gives an indication of any burning carbon particles in the gas stream. 
Further downstream is a flow restriction that is used to maintain a desired back pressure in the test section. The reactor pressure is 125 to $175 \mathrm{kPa}$ depending on the gas mass flowrate. The gas pressure drop through the reactor is between 4 and 8 percent. The gases after flowing through the restriction are essentially at ambient pressure. At this point water spray is used to reduce the exhaust stream gas temperature before the flow is vented.

\section{TEST CATALYSTS}

The catalysts tested were obtained from commercial sources in the form of $15 \mathrm{~cm}$ diameter monolithic discs. Specified were the disc thickness, disc diameter, number of flow-through passages per square centimeter of disc surface, but not the catalyst formulation or technique of application to the ceramic surfaces. These latter details are usually proprietary to each vendor. The catalyst pieces reported on in this paper were obtained from the Allied-Signal Company, Industrial Catalyst Division.

Previous testing had resulted in success in using reactor disc pieces made from nickel foil. The foil had been crimped and then rolled into a disc shape such that gases would flow between the crimps and adjacent wrapped around layers. One such disc was used in conjunction with some of the ceramic discs - either upstream or downstream of the ceramic pieces.

Six configurations were tested and are shown in a schematic axial crosssectional view in figure 4. Configurations 3 and 5 used platinum based catalyst applied to the ceramic surfaces; the other configurations had palladium based catalyst on the surfaces. The nickel foil disc was installed $1.2 \mathrm{~cm}$ after the ceramic pieces for configurations 3 and $15 \mathrm{~cm}$ before the ceramic pieces in configuration 5. Configurations 4 and 6 were tested with only ceramic pieces. Configuration 4 had $2.5 \mathrm{~cm}$ spaces or voids between the pieces and configuration 6 had the pieces pressed together. Configurations 12 and 14 made use of discs twice as thick as the previously used pieces. In addition configuration 12 had a nickel foil disc $5.5 \mathrm{~cm}$ downstream of the ceramic. Configuration 14 consisted of three double thick pieces made of a foamed ceramic material.

Initially the catalyst discs were sized to slide into the reactor section with a tight fit. Metallic clamping rings were installed upstream and downstream to make sure the pieces did not move. After suffering physical degradation of the ceramic pieces using this technique, a better method was eventually determined for cushioning the pieces from the reactor wall and from each other. This made use of high temperature ceramic cloth tape and roping. An example of this latter mounting technique is shown in figure 5 . The tape has been wrapped around each disc outer edge several times to fill any void space between the disc and the reactor wall. The ceramic roping is placed in a single wrap on the outer edge to insure the ceramic pieces do not touch each other when pressed into the reactor.

\section{TEST INSTRUMENTATION}

Gas temperatures and pressures were measured before and after the fuelair mixing nozzle; before, in, and after the catalyst reactor; and in the downstream exhaust and vent system. These temperatures and pressures, along 
with calculated fuel and air flowrates, are visually displayed in the test facility control room and are recorded for later computational determination of the desired result parameters.

A video display is presented in the control room showing the test rig internal reactor discharge gas flow stream. This display is recorded. A cell exterior video camera is used for overall scanning of the test facility including the exhaust gas burnoff flare.

During testing the reactor product gases are continuously sampled. In this program, the sample gases being the result of a fuel-rich reaction, have characteristics completely different from those obtained from a more conventional lean burn combustion reaction. Lean-burn product gases usually have high carbon dioxide and water contents whereas rich-burn products are high in carbon monoxide and hydrogen. This meant a different set of gas analyzers were required for the fuel-rich testing. These consisted of high concentration measuring nondispersive infrared carbon monoxide and hydrocarbon analyzers, a low concentration nondispersive infrared carbon dioxide analyzer, a low range chemiluminescent nitrogen oxides analyzer, a low range electrochemical oxygen measuring analyzer, and a thermal conductivity hydrogen analyzer. Each analyzer was zeroed and calibrated with known concentration span gases each test day.

A problem with sampling fuel-rich reaction gases is that any hydrogen and/or carbon monoxide in the gases tend to reduce nitrogen oxides, in the same sample, to nitrogen and water (ref. 2). This is especially likely to happen with hot gases $(>450 \mathrm{~K}$ ) in contact with stainless steel, nickel, or copper (ref. 3).

The average gas temperature was under $1375 \mathrm{~K}$ and this was achieved by controlling the fuel to air ratio. This was done to safeguard the catalyst material from spalling, sintering, or oxidizing. With this low temperature product gas it was possible to sample through uncooled probes made of various high temperature materials. The sample gas coming through the probe was quick-quenched immediately and passed through a gas cooler to bring its temperature down to $280 \mathrm{~K}$. At that temperature not only were any reactions quenched but any unreacted hydrocarbons and water were condensed. In this program the condensibles were not analyzed, but in previous work (ref. 4) they were determined to be hydrocarbons of the C6+ groupings and amounted to less than 10 percent of the gas stream.

The program test results were obtained from testing six catalyst configurations over a matrix test pattern consisting of mass flowrate, input air temperature, and the fuel to air ratio (ER). Test input conditions and steady-state operating results are presented in Table 1 for each of the six configurations. For comparison purposes, only those tests conducted at an input air temperature of approximately $920 \mathrm{~K}$ are presented; in addition, tests were carried out using 810 and $1050 \mathrm{~K}$ input air.

The tests were conducted at steady-state input conditions for 4 to $10 \mathrm{~min}$ durations. Usually a minimum of $4 \mathrm{~min}$ was needed to get stable gas analysis results. Typical test data are presented in figure 6 . For a series of tests using the configuration 3 reactor, the gas temperatures, averages values for a particular location at a given time, and the gas sample analysis, for hydrogen, carbon monoxide, carbon dioxide, and light-end hydrocarbons, for the four 
tests shown are presented as functions of operating time. Not shown is the time between individual tests. The input air flowrate was about $0.32 \mathrm{~kg} / \mathrm{sec}$ and $930 \mathrm{~K}$ for all four tests; the fuel to air ratio was varied from one test to the next: $4.3,4.7,5.1$, and $5.6 \mathrm{ER}$.

Figure 6 shows that as the ER increased, the precatalyst gas average temperature dropped with increased fuel flow. Likewise the gas temperatures between the catalyst discs also decreased. Temperature 1 is the gas temperature between disc 1 and 2 , temperature 2 is the gas temperature between disk 2 and 3, etc. The gas temperature downstream of the reactor, the average of 12 thermocouple valves, is labeled "AC" and is generally lower than temperature 4 which is immediately after the fourth and final catalyst piece. This drop in temperature can be attributed to thermal energy loss to the test section walls.

As the ER was increased, the figure 6 hydrogen and carbon monoxide data indicates decreasing concentrations. The hydrocarbons (reported as methane) and carbon dioxide tended to increase. Least stable in response were the oxygen and $\mathrm{NO}_{\mathrm{x}}$ data which were very low and had low response on the instruments being used.

\section{Results: Thermal Performance}

The chief objective of this first stage combustion process was to produce a combustible gaseous product that can be easily mixed with sufficient combustion air to bring about complete combustion at a fuel lean second stage condition. If there is enough residence or dwell time in the first stage setup, the liquid fuel can be vaporized with the incoming hot air, but at the expense of a temperature drop due to the vaporization process. The goal of this program was to not only vaporize the fuel and completely mix it with input air but to also bring about some degree of reaction so as to recover some of the thermal energy lost during vaporization. Hopefully, this can be accomplished by passing the vaporized fuel and air through a catalyst reactor.

The increase in thermal energy, in terms of the reactor discharge gas temperature rise over the input air temperature, is presented in figure 7 . The rise is an average temperature for each of the six tested configurations as a function of the test ER. Test conditions were at a nominal fuel-air mass flow of 0.3 to $0.6 \mathrm{~kg} / \mathrm{sec}$ and $920 \mathrm{~K}$ input air temperature. The temperature spread for a given configuration at a given ER, was about $\pm 25 \mathrm{~K}$. Testing was done over a range of ER's limited to maximum outlet gas temperatures of $1375 \mathrm{~K}$ or minimum stable operation.

Figure 7 results indicate that the platinum based catalyst material, plus a nickel disc, had the highest overall temperature gain between the input and output gas temperatures over the tested ER. Many of the palladium based catalyst configurations had a positive gain in temperature only at the lower ER's tested; at high ER's the gases never recovered back to the input air temperature after going through fuel vaporization. There was some gas temperature rise in going through the reactor but not enough to overcome the mass temperature drop in vaporizing the liquid fuel. 
The drop in the fuel and air mixture temperature during the fuel vaporization phase is presented in figure 8 as a function of the ER. The temperature drop increases as the quantity of fuel in the mix increases. For configurations $3,4,5$, and 6 , and the same operating conditions, the drop was about the same at a given ER; the variation being about \pm 10 percent. However, configurations 12 and 14 had vaporization temperature drops much greater than configurations that utilized catalyst discs only half as thick. Conjecture is that in using the thicker discs there is less heat transfer from the downstream reaction region to the upstream disc face where input fuel and air can come in contact with the catalyst surface. Also with the thicker discs there is a greater pressure drop and more reason for the upstream gases to be stagnant before flowing through the catalyst piece passages. The thinner discs, with less flow resistance, have increased turbulence in the flow passages and in the voids before and after each disc. This would encourage heat transfer and reaction occurring closer to the upstream catalyst face.

The overall temperature rise shown in figure 7 includes increases in the mass gas temperatures while flowing through the catalyst ceramic material, plus, in the case of configurtations 3, 5, and 14, through the nickel disc pieces. The mass temperature rise through only the catalyst ceramic portion of each configuration is shown in figure 9 as a function of the ER. The platinum based catalyst (configuration 3 ) and the palladium based catalyst (configuration 4) appear to have about the same temperature rises between an $\mathrm{ER}$ of 4 and 6 .

The configuration mounting technique appears to have an influence on mass temperature rise. Configurations 3,4 and 14 were mounted with spacing between the individual ceramic discs, whereas configurations 5, 6, and 12 had the ceramic discs as close together as possible. The spacing between the discs apparently allows the gases exiting one disc to intermix and homogenously, and uniformly, react together before flowing into the passages of the next downstream disc. On the other hand, those discs packed tightly together tend to direct the mass flow through an almost continuous ceramic passage where most of the reaction can only be heterogeneous on the catalyst surfaces.

The loading factor, i.e., the optimum mass flowrate per active catalyst surface area, was highest with configuration 4 where it ranged from 0.03 to $0.05 \mathrm{~g} / \mathrm{sec} / \mathrm{cm}^{2}$. It appears, as shown in figure 9, that the greatest reaction activity was at a mass flowrate of about $450 \mathrm{~g} / \mathrm{sec}$ and flowrates greater or smaller than this resulted in lower overall temperature rises.

The temperature pattern of the reaction gases flowing out of the reactor also revealed a trend that was influenced by the type of catalyst being tested. The temperatures of the reactor discharge gases from the six test configurations are presented in figure 10 for tests conducted at similar conditions. These are circumferential gas temperatures measured at steadystate operating conditions. The average value of each set is presented along with the high and low variations among the given set. With the platinum containing catalyst the variation was +15 and $-14 \mathrm{~K}$ for configuration 3 and +54 and $-32 \mathrm{~K}$ for configuration 5 . For the palladium containing catalyst configurations the gas temperature variations were as high as +419 and as low as $-460 \mathrm{~K}$ (configuration 6 ); the biggest variations being for configurations with the catalyst discs stacked close together. 
Another interesting temperature was that measured in the gas stream just before the pressure restriction; this was about 10 pipe diameters downstream of the catalyst reactor. For most of the tests the gas temperature leveled out at about 1250 to $1350 \mathrm{~K}$, even for those tests where the reactor discharge gas temperatures were about $1000 \mathrm{~K}$. This would indicate that homogeneous gas reactions were occurring in the flow stream volume after the reactor.

Therefore, the importance of the catalytic reactor is initiating a heterogeneous reaction which, given additional residence time downstream of the reactor, will result in continuing homogeneous reactions before additional air is mixed into the mass for subsequently second stage combustion. The problem with reactor configurations having wide variations in exit gas temperature is that some portions of the mass flow are going through the reactor without even undergoing any heterogeneous reaction and other portions are over-reacting in the catalyst and bringing about over temperature catalyst destruction (e.g., configurations 12 and 14 ).

\section{Results: Emission Characteristics}

The gas sampling for emission determination is done using a center line gas stream probe to remove about $5 \mathrm{~L} / \mathrm{min}$ of reaction gas continuously during any test sequence. After sampling the gas sample is cooled to ambient temperature to remove the heavy-end hydrocarbon products and the remaining gas is subdivided into portions passed through the individual component gas analyzers.

The nitrogen oxides $\left(\mathrm{NO}_{\mathrm{x}}\right)$ in the reactor discharge gas stream are presented in figure 11 for the tested catalyst configurations. They are presented as a function of the gas stream average temperature which is a function of the operating ER. There is much scatter in the data because of the low values being at the minimum measuring capabilities of the analyzer. The general trend appears to be a maximum $\mathrm{NO}_{\mathrm{x}}$ concentration of $14 \mathrm{ppm}$ which corresponds to an emission index value of about $0.08 \mathrm{~g} / \mathrm{kg}$ fuel consumed. There appears to be a trend for the NO concentration to peak at an operating temperature of 1100 to $1200 \mathrm{~K}$, especially at the higher mass flowrates. This might be indicative of a reduction of $\mathrm{NO}_{\mathrm{x}}$ at higher temperatures where there is a greater concentration of hydrogen and carbon monoxide to react with the $\mathrm{NO}_{x}$. As the reaction temperature decreases, so does the hydrogen and carbon monoxide concentrations allowing more of the NO to proceed downstream unreacted. At temperatures of less than $1100 \mathrm{~K}^{\mathrm{x}}$ there is less tendency for the air stream nitrogen to be oxidized to $\mathrm{NO}_{\mathrm{x}}$.

The concentration of the gas stream carbon monoxide (CO) is presented in figure 12 for the various configurations, again as a function of the reaction gas temperatures. There is scatter in the data, but if only the configuration 3 data is examined, the co concentration increases from about 5 vol $\%$ at $1200 \mathrm{~K}$ to about 8 vol \& at a $1400 \mathrm{~K}$ gas stream temperature. These measured concentrations are much lower than theoretical calculations (22 to 26 vol $\%$ ) for Jet-A and air reacting at these indicated operating conditions. Ted Brabbs in doing similar testing in a lab bench rig (ref. 4) obtained co concentrations about twice that shown in figure 12 .

The concentration of hydrogen $\left(\mathrm{H}_{2}\right)$ in the reactor product gases is presented for the tested configurations in figure 13 as a function of the gas 
stream temperature. Most of the data values are for configurations 3 and 5 . As the gas temperature increased from 1100 to $1400 \mathrm{~K}$, the configuration $5 \mathrm{H}_{2}$ concentration went from about 5 to 10 vol \%; for configuration 3 the $\mathrm{H}_{2}$ concentration went from 3 to 9 vol $\%$. Both configurations had essentially the same ceramic catalysts but 3 had the nickel disc downstream of the ceramic pieces and 5 had the nickel disc upstream of the ceramic pieces. It is possible that configuration 3 product $\mathrm{H}_{2}$ is being used to reduce the oxide coating on the nickel disc surfaces. To check this, nickel discs alone were tested at similar operating conditions and the results, shown in figure 13 , show a marked reduction of $\mathrm{H}_{2}$ production for similar operating conditions.

\section{Results: Catalyst Physical Degradation}

A problem using the ceramic disc catalysts has been the physical integrity of the monolithic material. Initial problems had to do with disc cracking with thermal cycling operation. This is illustrated in figure 14 where four 25-mm thick ceramic monolith discs are shown in their original received state and then at the conclusion of their test program. Each of the discs has cracked into various size segments and only the compactness of the configuration kept the discs together through the testing sequence. Sudden coolingdown of the reactor at the conclusion of a given test day also contributed to the high stress factors that would crack the monolithic structure. After several trial and error approaches, it was found that cushioning the discs with high temperature ceramic cloth tape and rope relieved this problem as is shown in figure 5 .

Another problem, evident with the thicker discs, was localized hot spots or over-temperature regions inside or on the end surfaces of the catalyst disc. These hot spots have high enough temperatures to melt and/or vaporize the ceramic substrate. This is exemplified by a photograph, figure 15, of configuration 14 foamed ceramic test discs. The photograph shows the downstream end of each disc. The discs were about $2 \mathrm{~cm}$ apart in the test rig. The second disc had a localized hot region that destroyed or melted a portion of the ceramic foam. The melted ceramic and catalyst deposited on the upstream face of the third disc. With partial flow blockage in the third disc, it had hot spots which resulted in end melting. What with deposits and voids in the discs the gas flow through the reactor was uneven and the gas temperature distribution fluctuated even more. A similar situation occurred with the configuration 12 reactor. It too consisted of 55-mm thick discs. A hot region occurred between the two discs which melted the catalyst and ceramic such that it flowed downstream. The weakened second disc broke apart. The pieces of the broken disc, solidified melted catalyst, and ceramic cloth disc wrap lodged on the upstream side of the nickel disc. This resulted in overheating of portions of the nickel foil and it melted. What was left of the nickel foil disc after testing had soot deposits on the downstream face. This was the only situation during the test program that soot, or carbon deposits, were observed on the test pieces. It does not appear that simply increasing the thickness of the catalyst containing discs will give improved results. 


\section{CONCLUSIONS}

The test program results indicate the following:

1. For the flowrates of fuel and air tested, a hot stream of combustible gases can be produced when using either platinum based or a palladium based ceramic monolith reactor.

2. A sustained reaction was attained at input air temperatures greater than $900 \mathrm{~K}$ at reactor loading levels of approximately 0.03 to $-0.05 \mathrm{~g}$ fuel/sec $/ \mathrm{cm}^{2}$ of active catalyst surface.

3. The reactor output gases contained about 50 percent of the theoretical hydrogen and carbon monoxide for the attained gas temperature levels and very low quantities of $\mathrm{NO}_{x}$.

4. The technique used to mount the ceramic catalyst pieces in the reactor as well as the sizing of the pieces is critical in order to maintain physical integrity of the unit.

\section{REFERENCES}

1. Brabbs, T.A.; Rollbuhler, R.J.; and Lezberg, E.A.: Fuel-Rich Catalytic Combustion - A Fuel Processor for High Speed Propulsion. NASA TM-103177, 1990.

2. Samuelsen, G.S.; and Harman, J.N.: Chemical Transformations of Nitrogen Oxides When Sampling Combustion Products. Univ. of Calif.-Irvine, J. Air Pollution Control, vol. 27, no. 7, July 1976, pp. 648-655.

3. England, C.; Houseman, J.; and Teixeira, D.P.: Sampling Nitric Oxide From Combustion Gases. Combust. Flame, vol. 20, June 1973, pp. 439-442.

4. Brabbs, T.A.; and Gracia-Salcedo, C.: Fuel Rich Catalytic Combustion Using Jet-A Fuel. NASA TM-101975, 1989.

5. Jones, R.E., et al.: Combustion Gas Properties I-ASTM Jet-A Fuel and Dry Air. NASA TP-2359, 1984. 


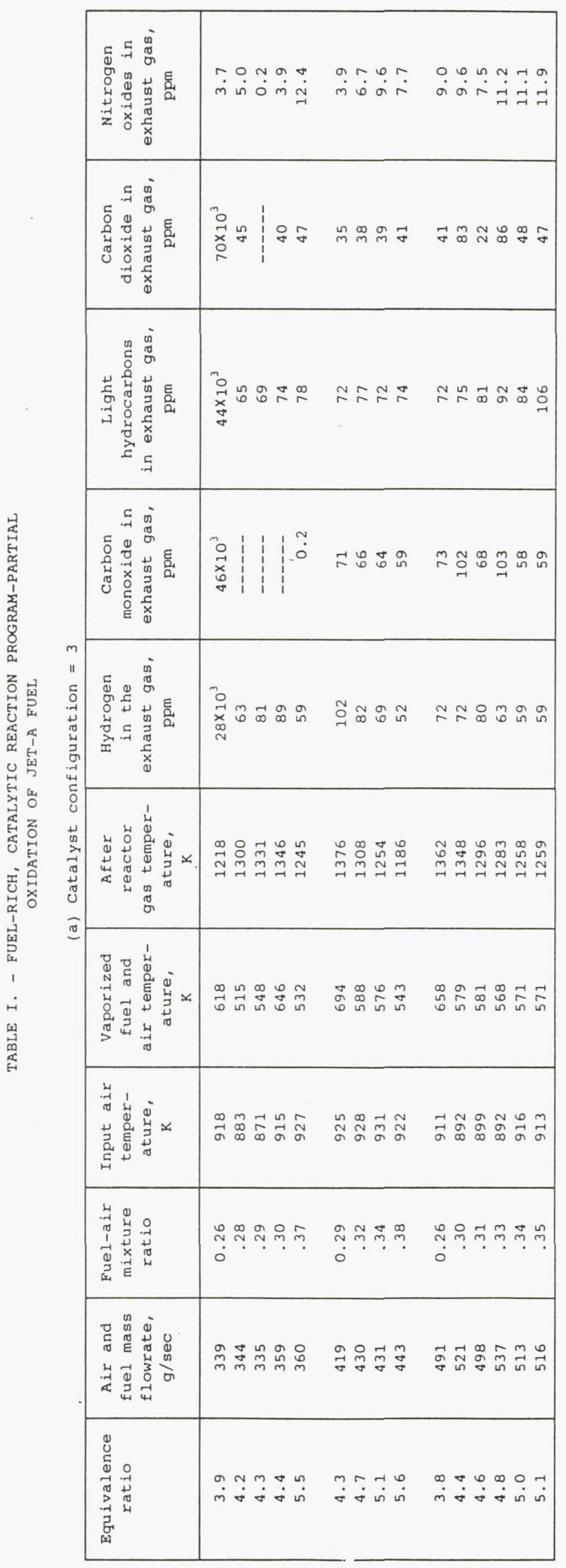

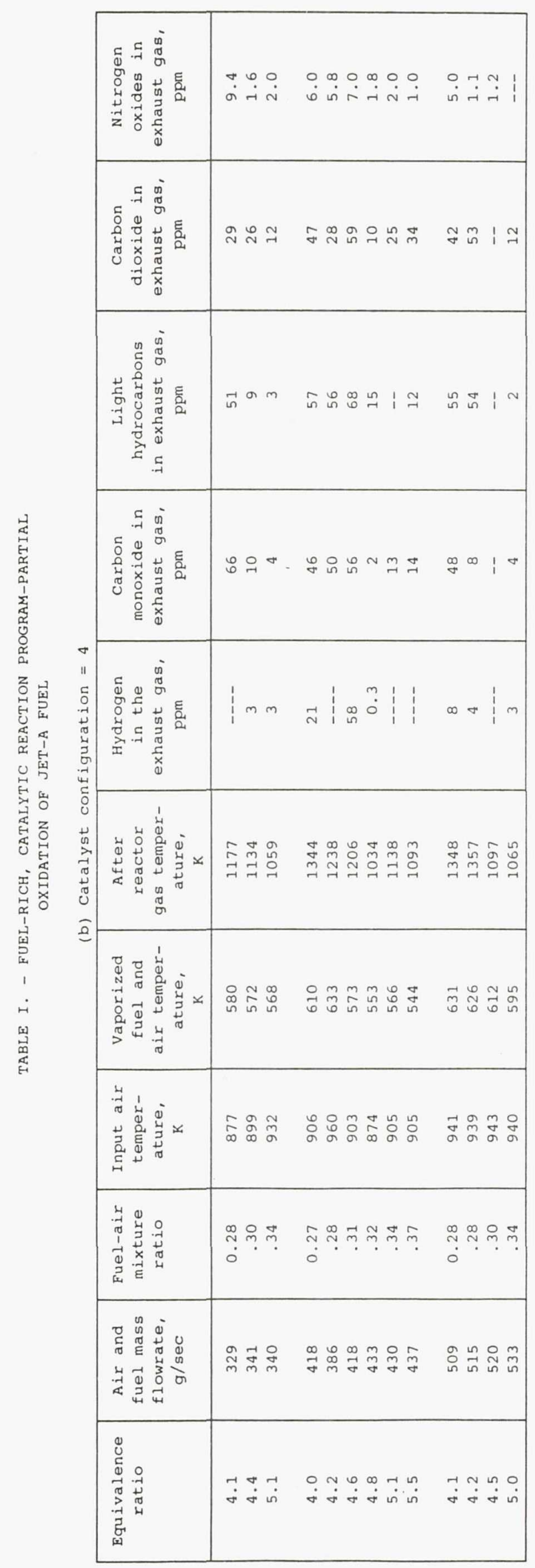




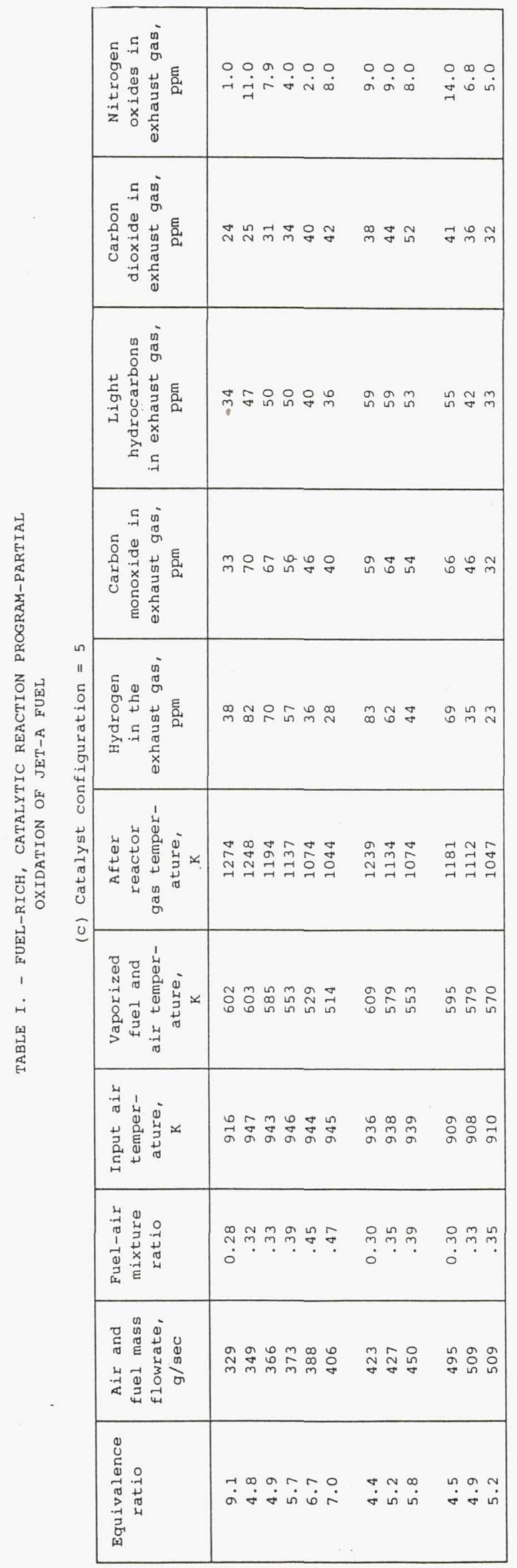

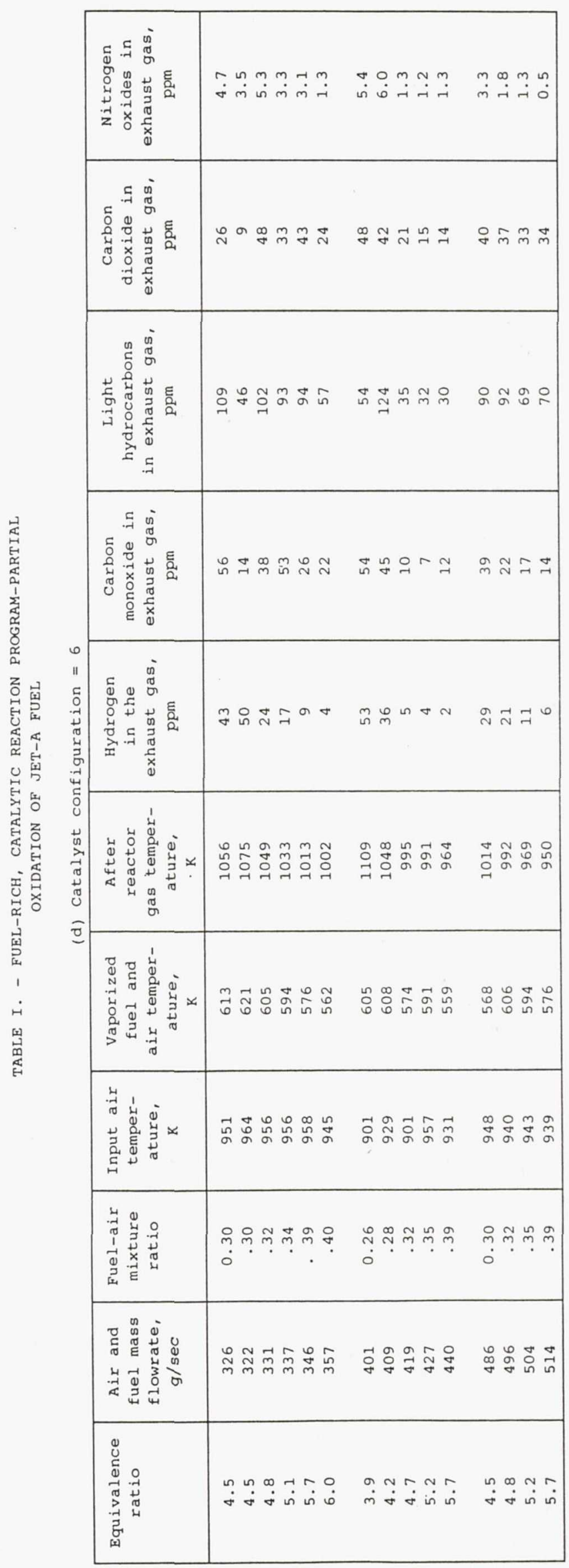




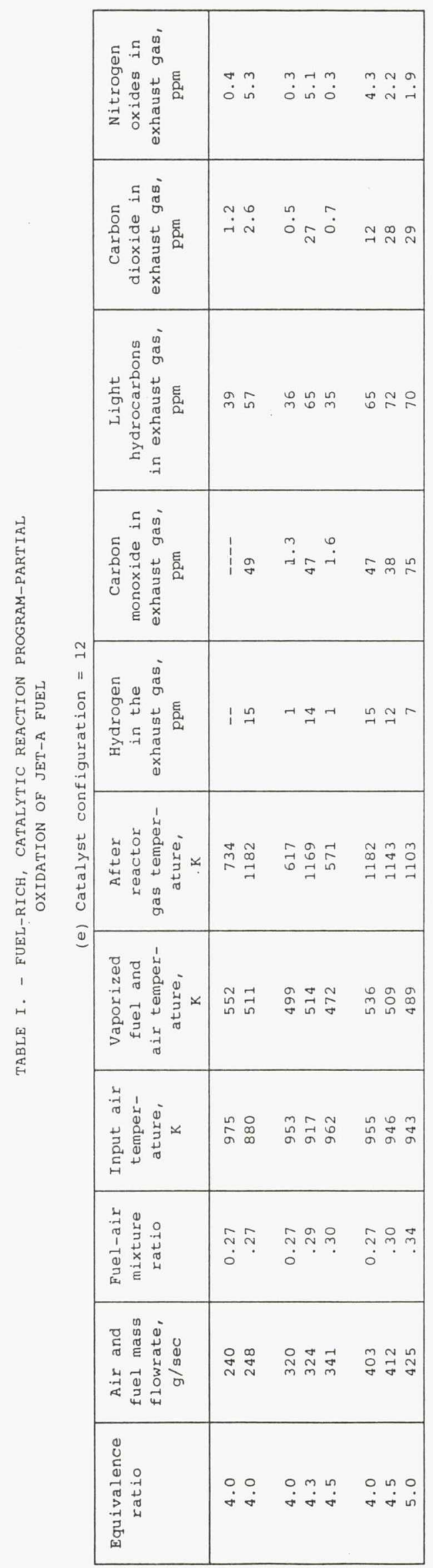

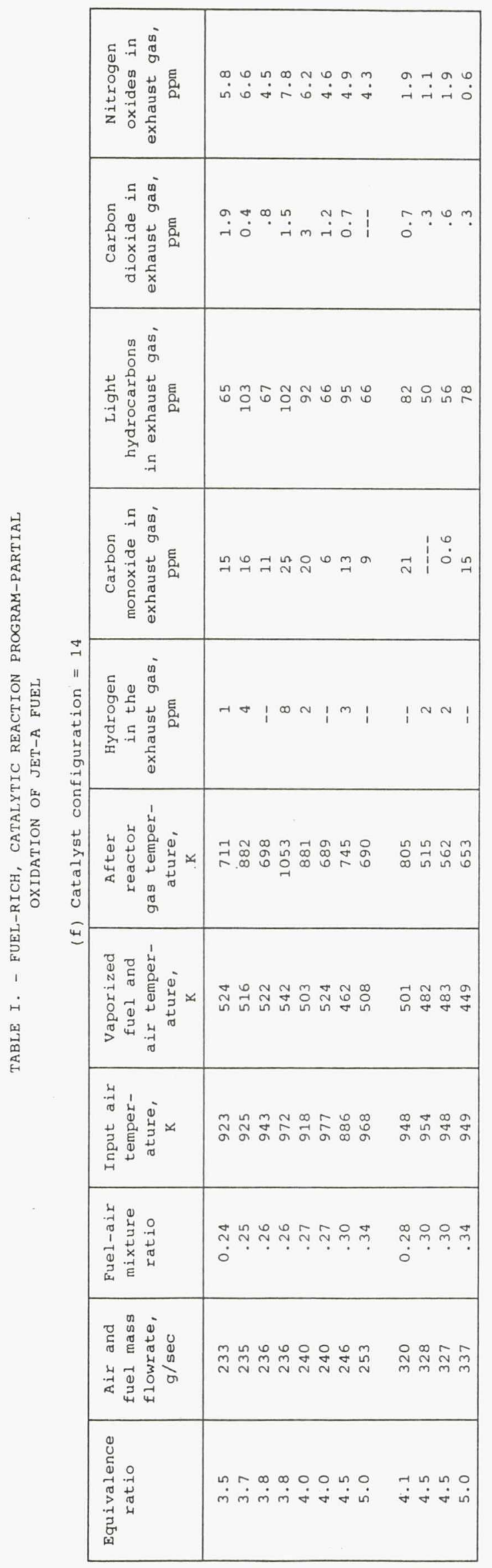




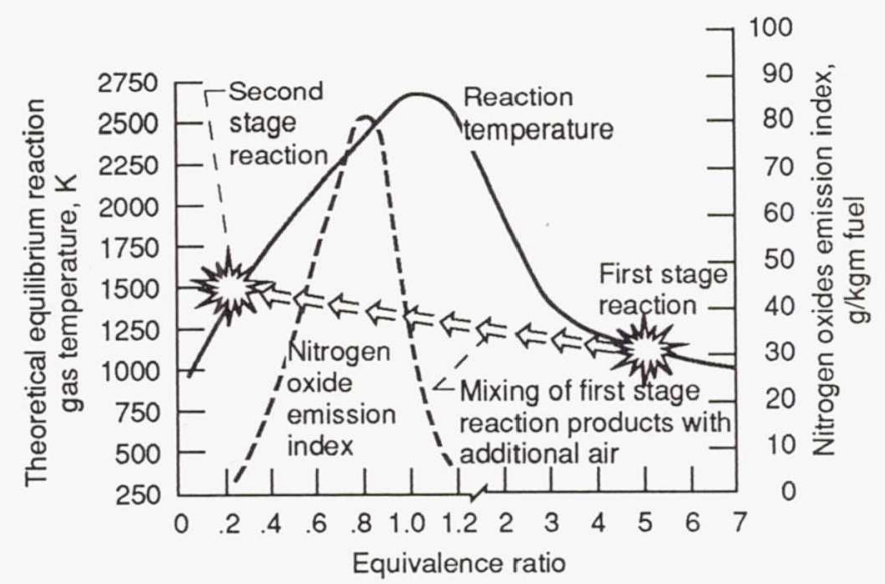

Figure 1.-Reaction of jet-A fuel with $860 \mathrm{~K}$ air (ref.: NASA TP 2359 and LeRC calculations by C.B. Salcedo).

Features:

- Combustor test air flows up to $1 \mathrm{kgm} / \mathrm{sec}$

- Air temperatures from ambient to $1250 \mathrm{~K}$

- Air pressures from 1-10 atm

- Liquid or gaseous fuel flows

- Can flow a variety of fuels

- Rapid change capability of above parameters

- Gaseous emissions determination

- Exhaust gases clean-up system

- On-line date acquisition system

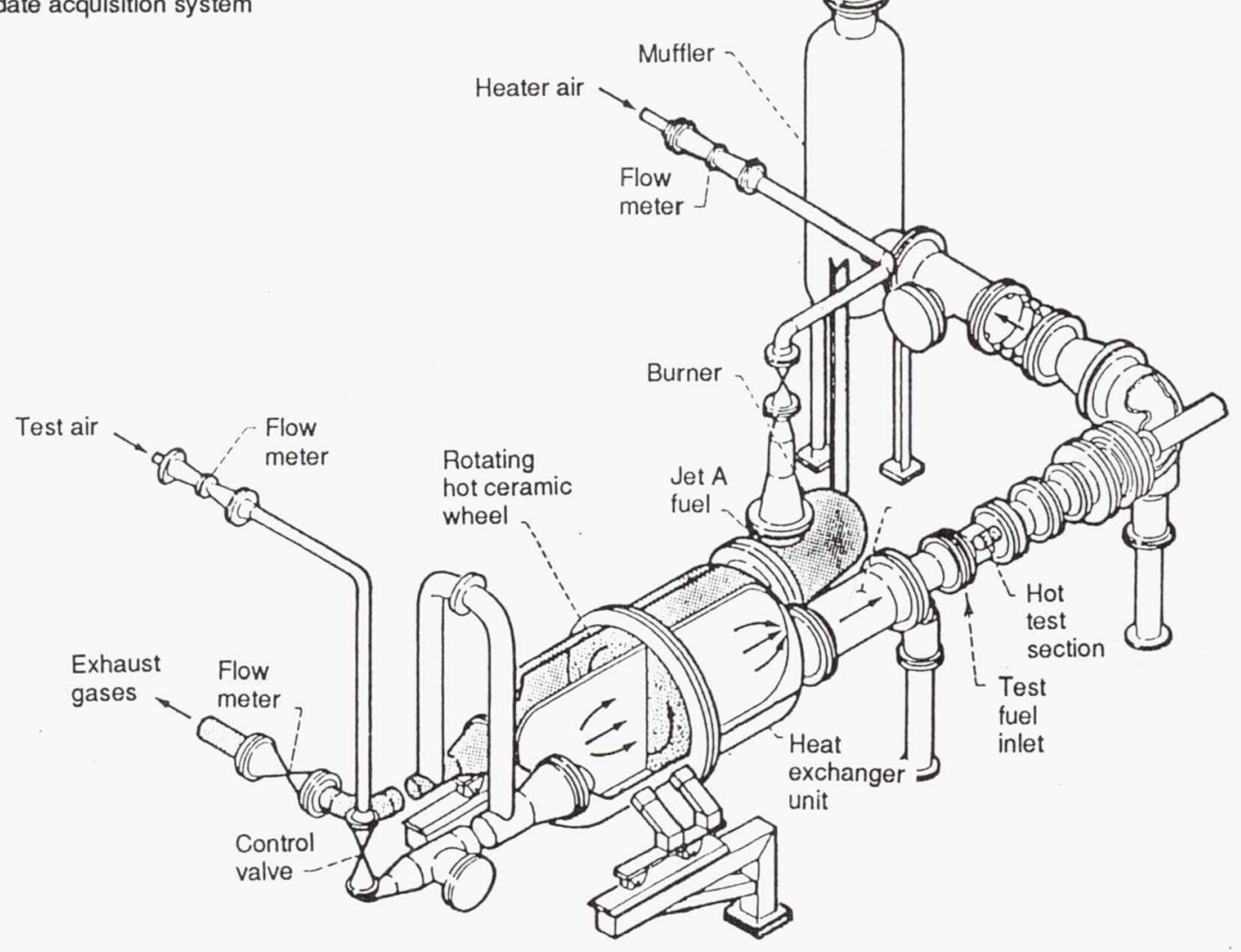

Figure 2.-High temperature transient facility, cell 23 C.R.L. 


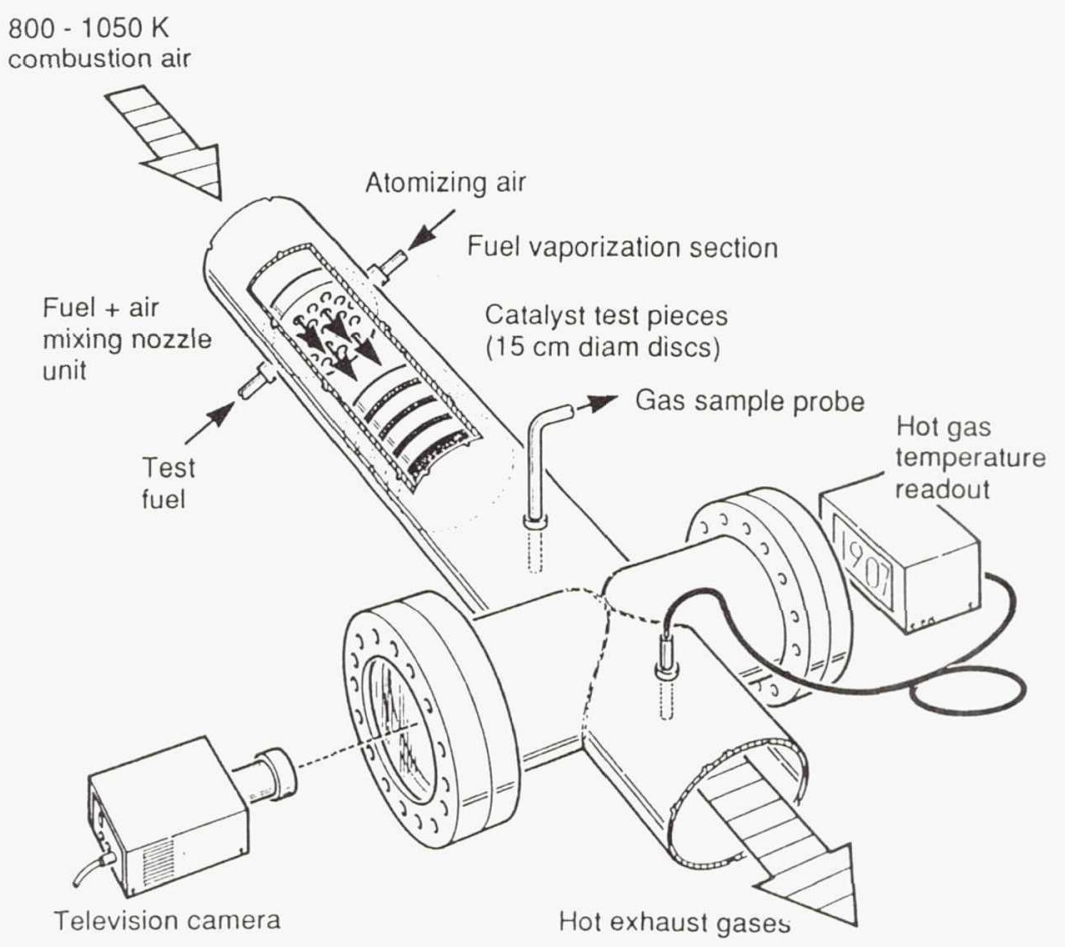

Figure 3.-Fuel-rich, catalytic reaction program hot test section. 


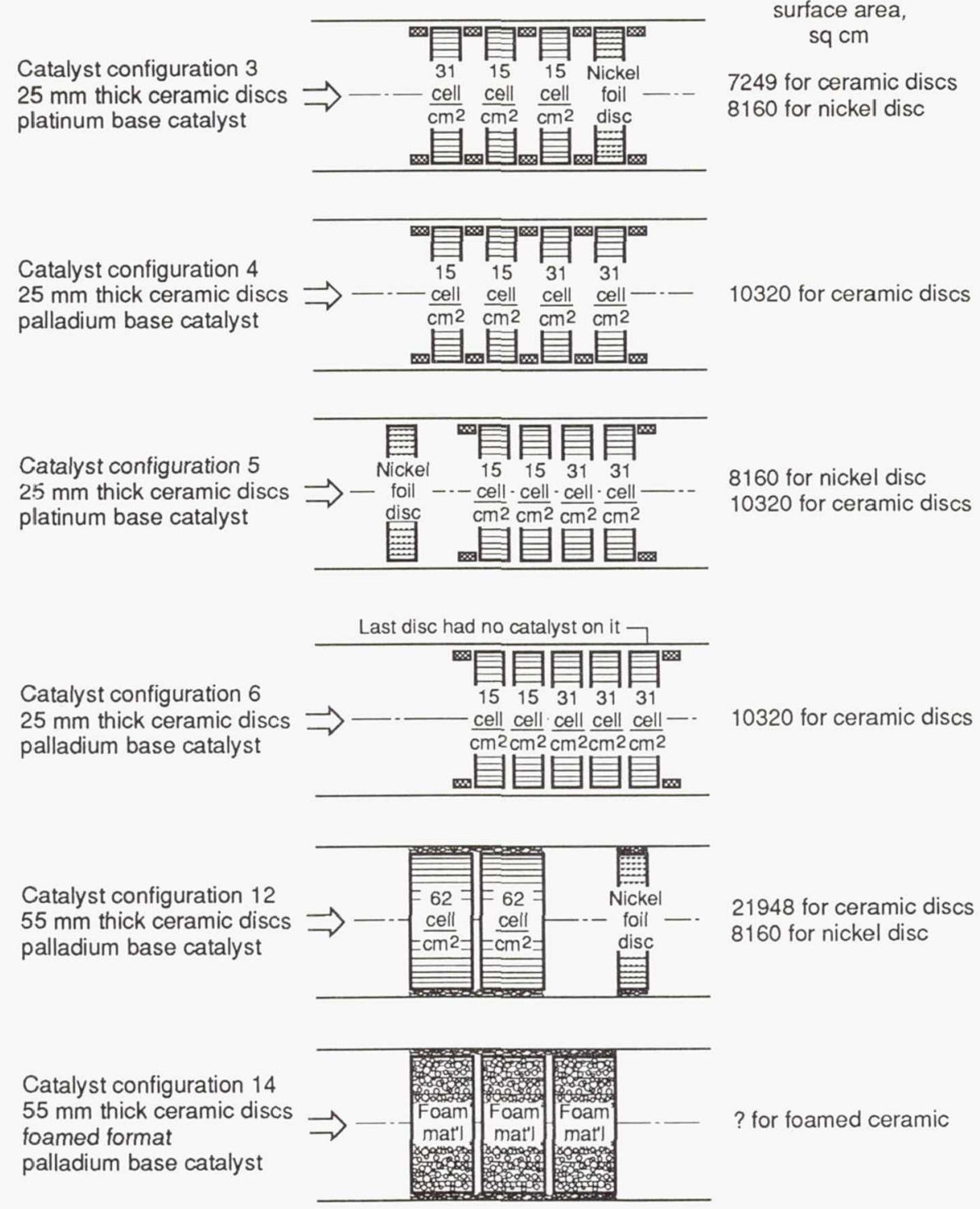

Active catalytic urface area,

7249 for ceramic discs

$25 \mathrm{~mm}$ thick ceramic dis platinum base catalys

cell cell cell foil

$\mathrm{cm}^{2} \mathrm{~cm}^{2} \mathrm{~cm}^{2}$ disc 8160 for nickel disc

10320 for ceramic discs

8160 for nickel disc

platinum

10320 for ceramic discs

21948 for ceramic discs

8160 for nickel disc

$55 \mathrm{~mm}$ thick ceramic disc

palladium base catalyst

Figure 4.-Test program catalytic reactor configurations. Mounted in a $15.3 \mathrm{~cm}$ diam duct. 


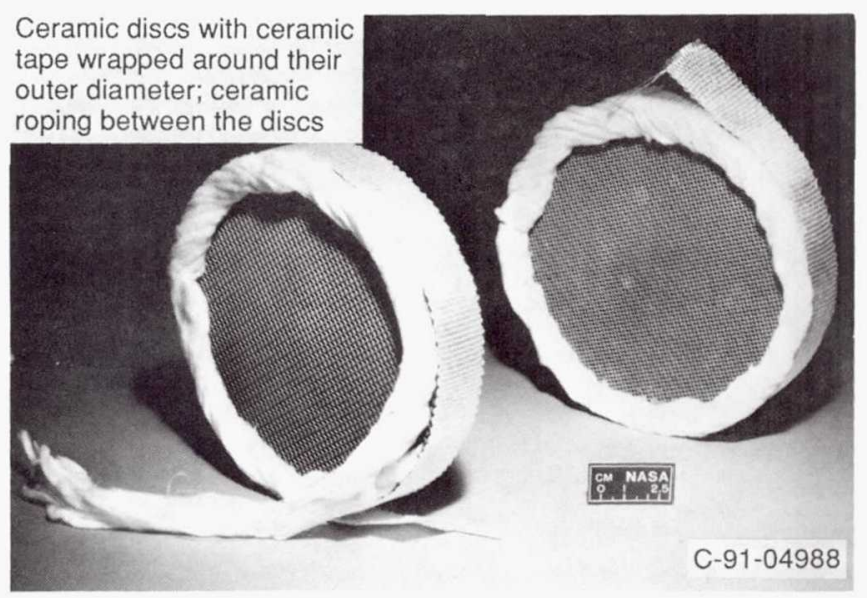

Figure 5.-Fuel-rich catalytic reaction test program disc mounting technique.

Catalyst configuration 3

$\mathrm{PC}=$ Average pre-catalyst gas temperature

1 = Average gas temperature after catalyst disc \#1

2 = Average gas temperature after catalyst disc \#2

3 = Average gas temperature after catalyst disc \#3

4 = Average gas temperature after catalyst disc \#4

$A C=$ Average after reactor gas temperature

Test A

$419 \mathrm{~g} / \mathrm{s}$ mass $925 \mathrm{~K}$ Tair $153.8 \mathrm{KPa}$

4.3 ER

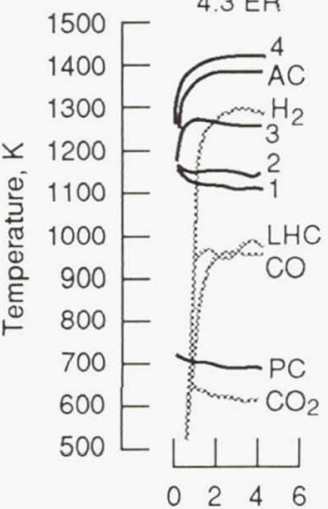

Test B

$430 \mathrm{~g} / \mathrm{s}$ mass $928 \mathrm{~K} \mathrm{~T}_{\text {air }}$

$154.4 \mathrm{KPa}$

4.7 ER

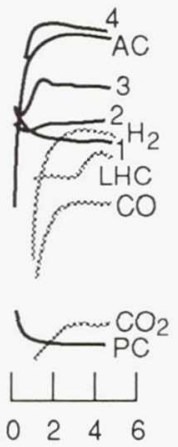

Test C

$431 \mathrm{~g} / \mathrm{s}$ mass

$931 \mathrm{KT}_{\text {air }}$

$149.0 \mathrm{KPa}$

5.1 ER

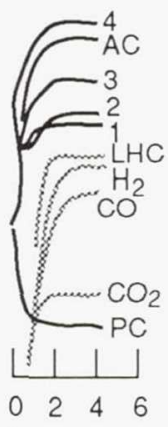

Test D

$444 \mathrm{~g} / \mathrm{s}$ mass $922 \mathrm{~K} \mathrm{~T}_{\text {air }}$

$144.8 \mathrm{KPa}$

$5.6 \mathrm{ER}$

Figure 6.-Fuel-rich, catalytic test program typical output data as a function of test time. 


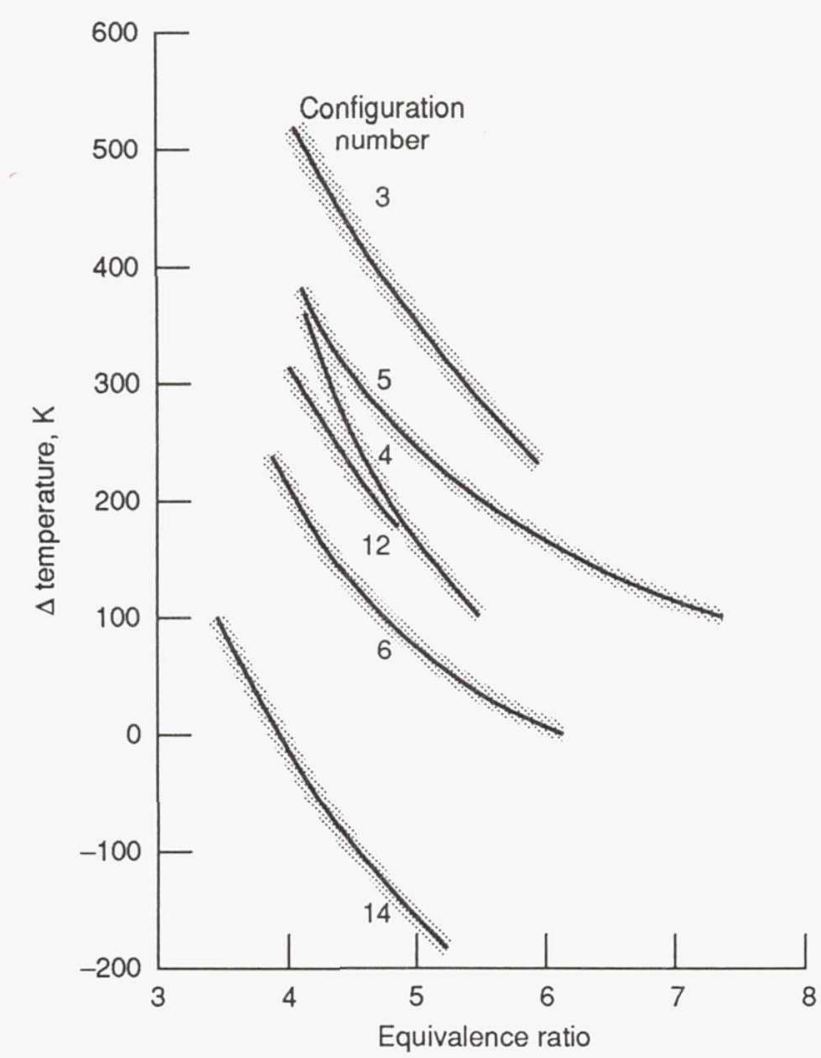

Figure 7.-Fuel-rich, catalytic reaction test program overall temperature change from input air temperature to reactor exhaust. Data from $0.40 \mathrm{kgm} / \mathrm{sec}$ mass flow; $920 \mathrm{~K}$ input air temperature.

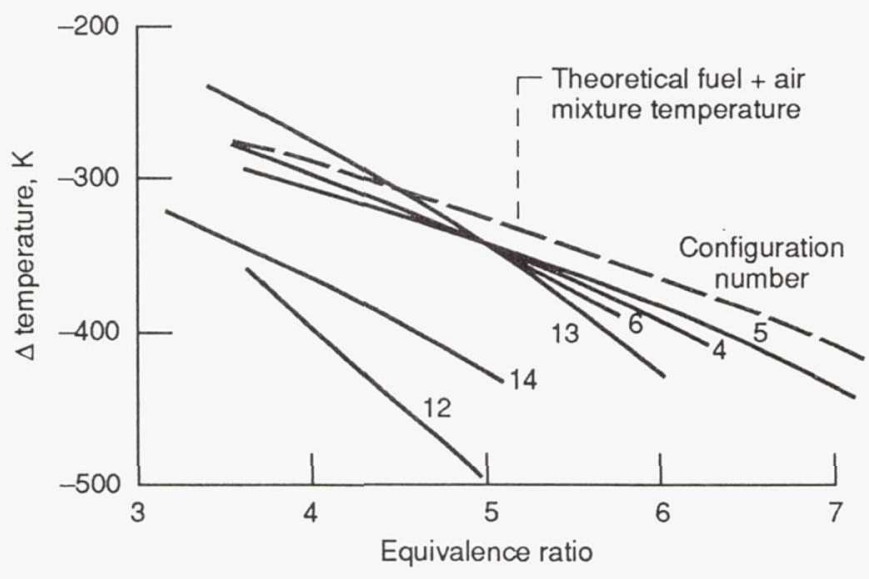

Figure 8.- Gas temperature drop from that of input air temperature to entering the catalytic reactor. Data from $0.40 \mathrm{kgm}$ mass flow $/ \mathrm{sec}$; input air temperature nominal $920 \mathrm{~K}$.

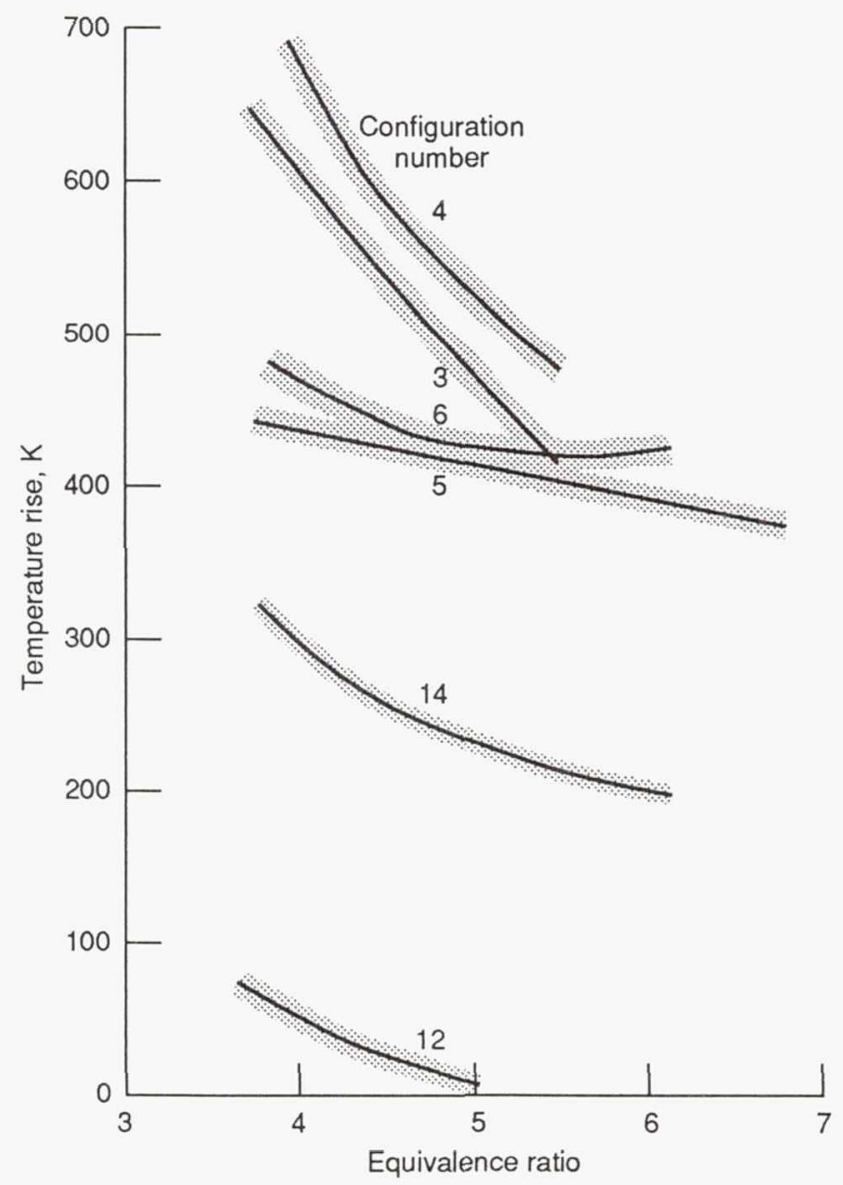

Figure 9.-Fuel-rich, catalytic reaction program rise in gas temperature across the ceramic catalyst pieces. Data from $0.40 \mathrm{kgm}$ mass flow $/ \mathrm{sec}$; input air temperature nominal $920 \mathrm{~K}$. 
Configuration 3

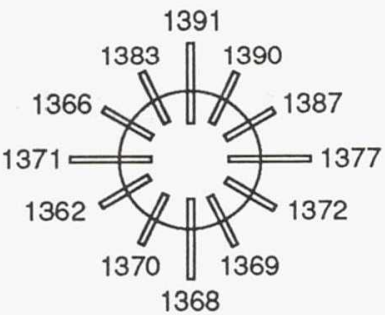

Average $=1376 \mathrm{~K}(+15 /-14)$

Configuration 6

937

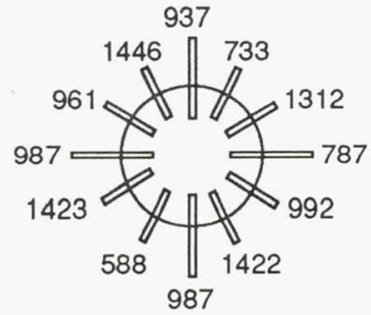

Average $=1047 \mathrm{~K}(+419 /-460)$
Configuration 4

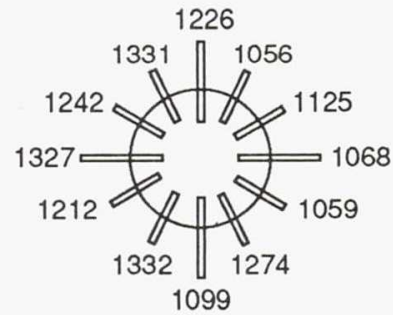

Average $=1216 \mathrm{~K}(+116 /-160)$

Configuration 12

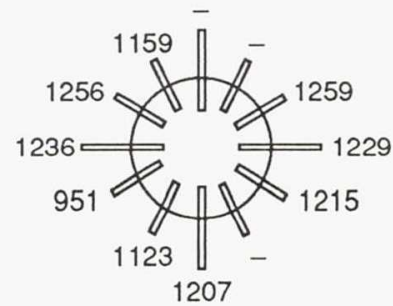

Average $=1182 \mathrm{~K}(+77 /-231)$
Configuration 5

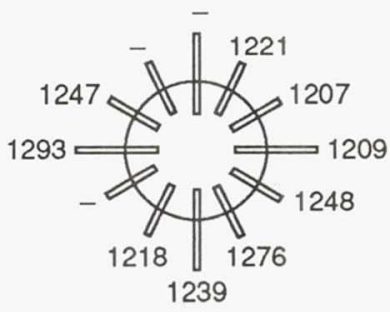

Average $=1293 \mathrm{~K}(+54 /-32)$

Configuration 14

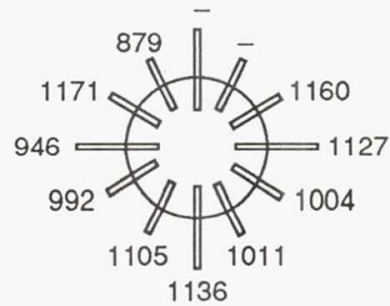

Average $=1053 \mathrm{~K}(+118 /-174)$

Figure 10.-Circumferential gas temperatures downstream of the catalyst reactor typical test data for each tested configuration. Nominal flow rate of $0.4 \mathrm{kgm} / \mathrm{sec} ; 935 \mathrm{~K}$ input air; $4.2 \mathrm{ER}$. View looking downstream. All temperatures measured approximately $4 \mathrm{~cm}$ from the duct centerline.

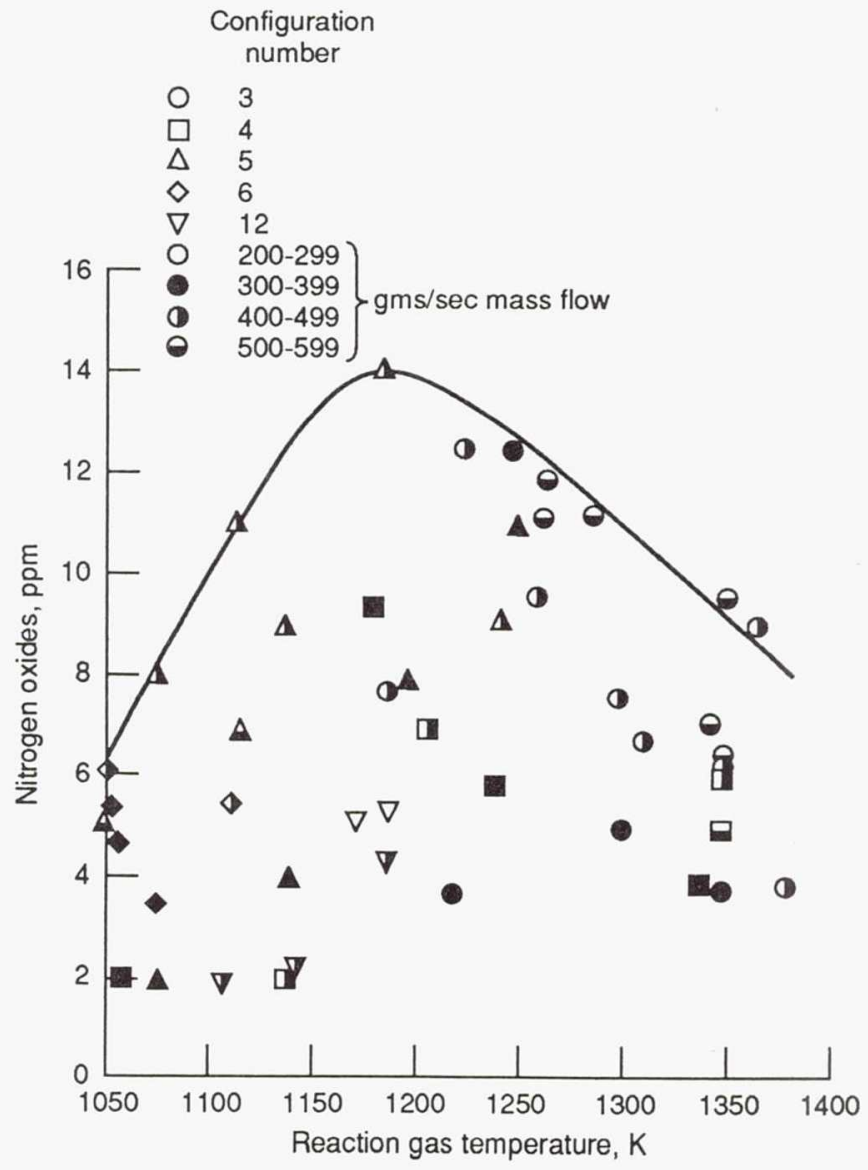

Figure 11.-Nitrogen oxides $\left(\mathrm{NO}_{x}\right)$ concentration in the reaction gases. Input air temperature nominally $920 \mathrm{~K}$. 


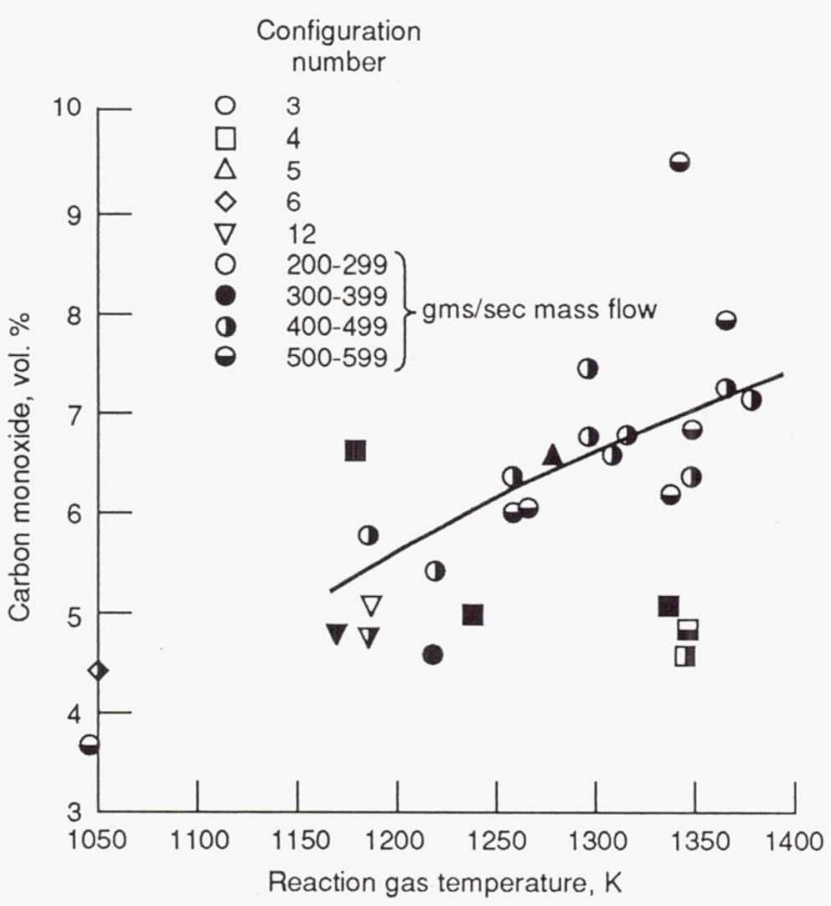

Figure 12.-Carbon monoxide concentration in the reaction gases; input air temperature nominally $920 \mathrm{~K}$.

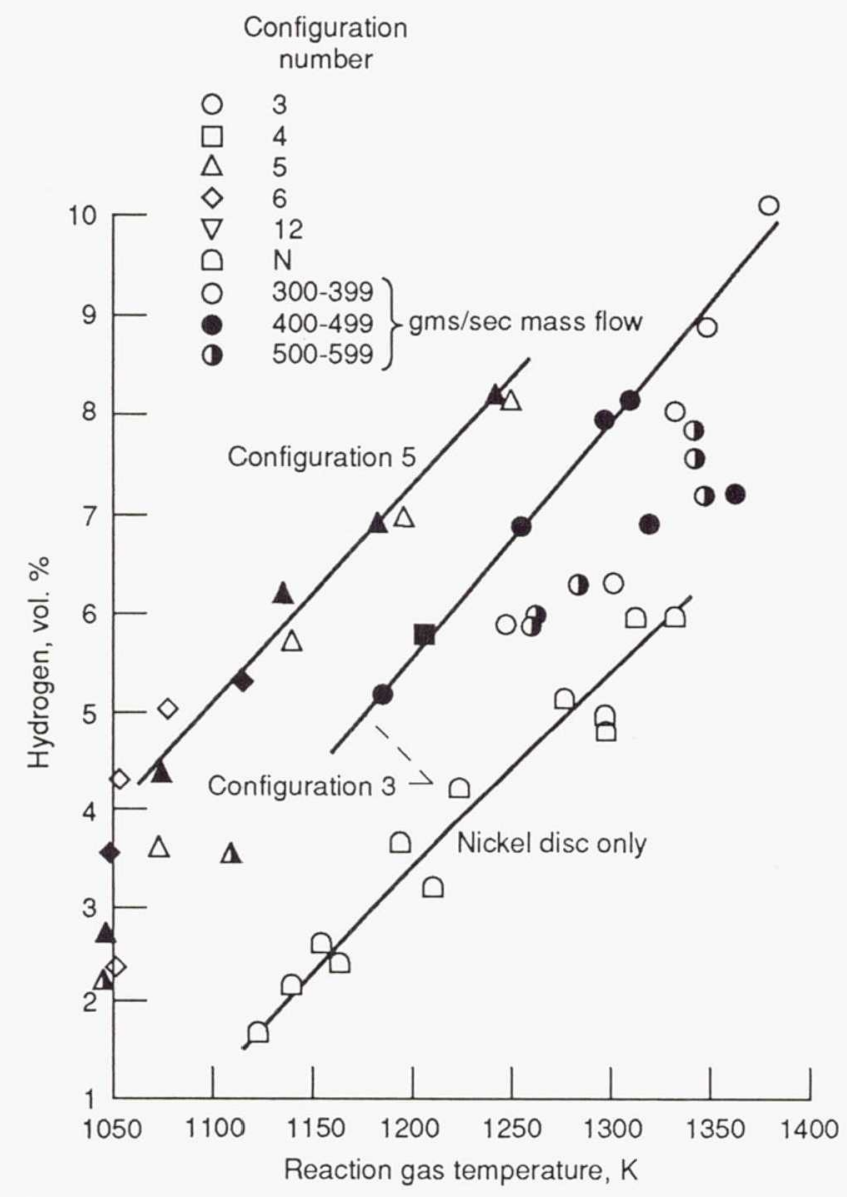

Figure 13.-Hydrogen concentration in the reaction gas; input air temperature nominal $920 \mathrm{~K}$.

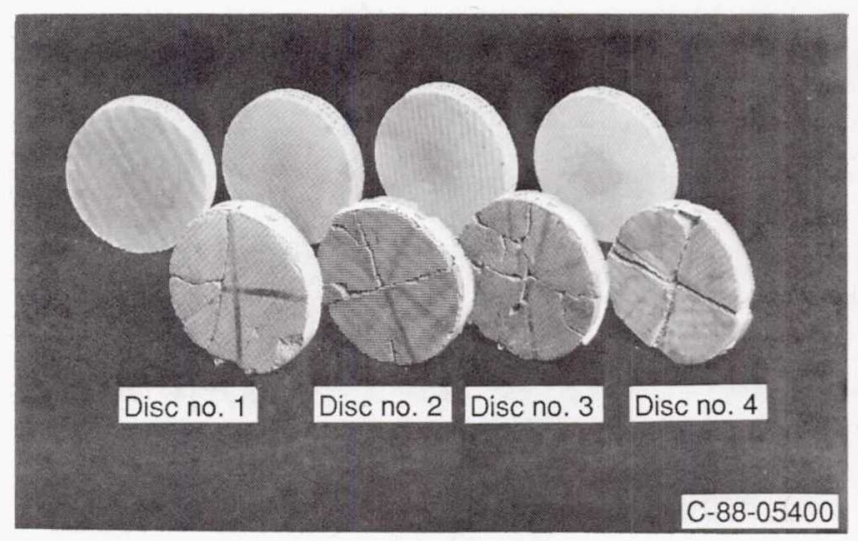

Figure 14.- Honey-comb ceramic material catalyst reaction units before and after testing.

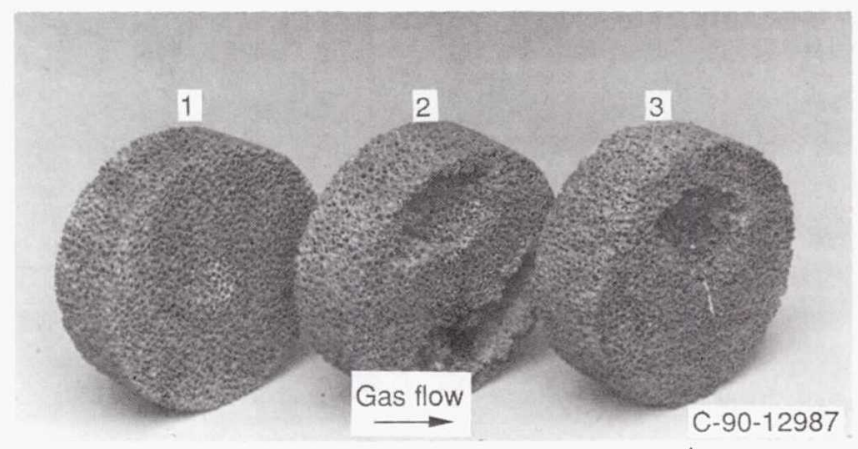

Figure 15.-Downstream side of catalyst configuration 14 foamed ceramic pieces. Post run destruction from localized thermal excess. 
- A catalytic reactor using either platinum based, or palladium based, catalyst is a dependable source of hot combustible gases over a range of fuel-rich input conditions.

- A sustained reaction can be initiated and maintained when the input air temperature is greater than $900 \mathrm{~K}$ and the catalyst loading is about $.03-.05$ grams of fuel and air $/ \mathrm{sec} / \mathrm{sq} \mathrm{cm}$ of catalyst surface.

- The product gases from such a fuel-rich oxidation reaction are very low in nitrogen oxides.

- A technique has been developed for mounting the ceramic catalysts to minimize thermal shock destruction.

Figure 16.-Program conclusions.

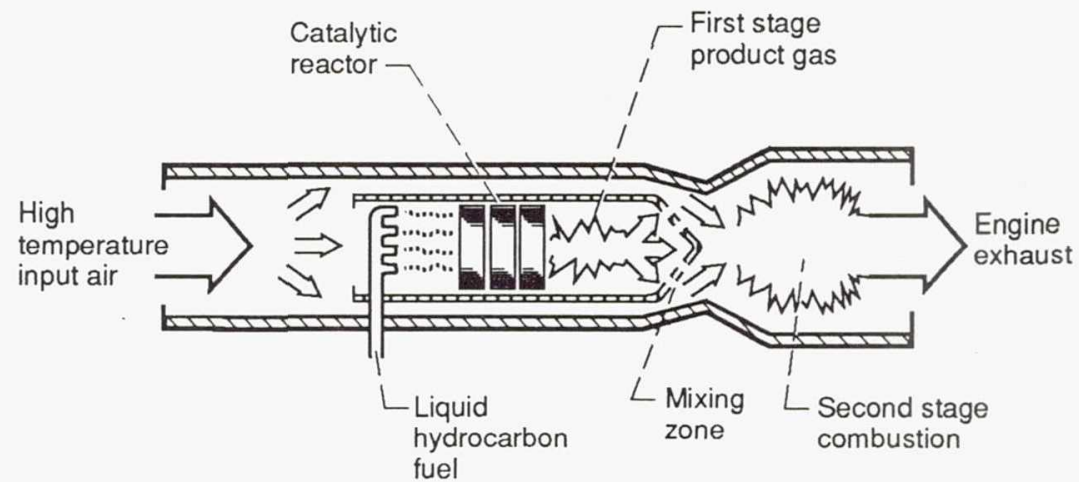

Figure 17.-Two stage, catalytic initiated, combustor concept. 


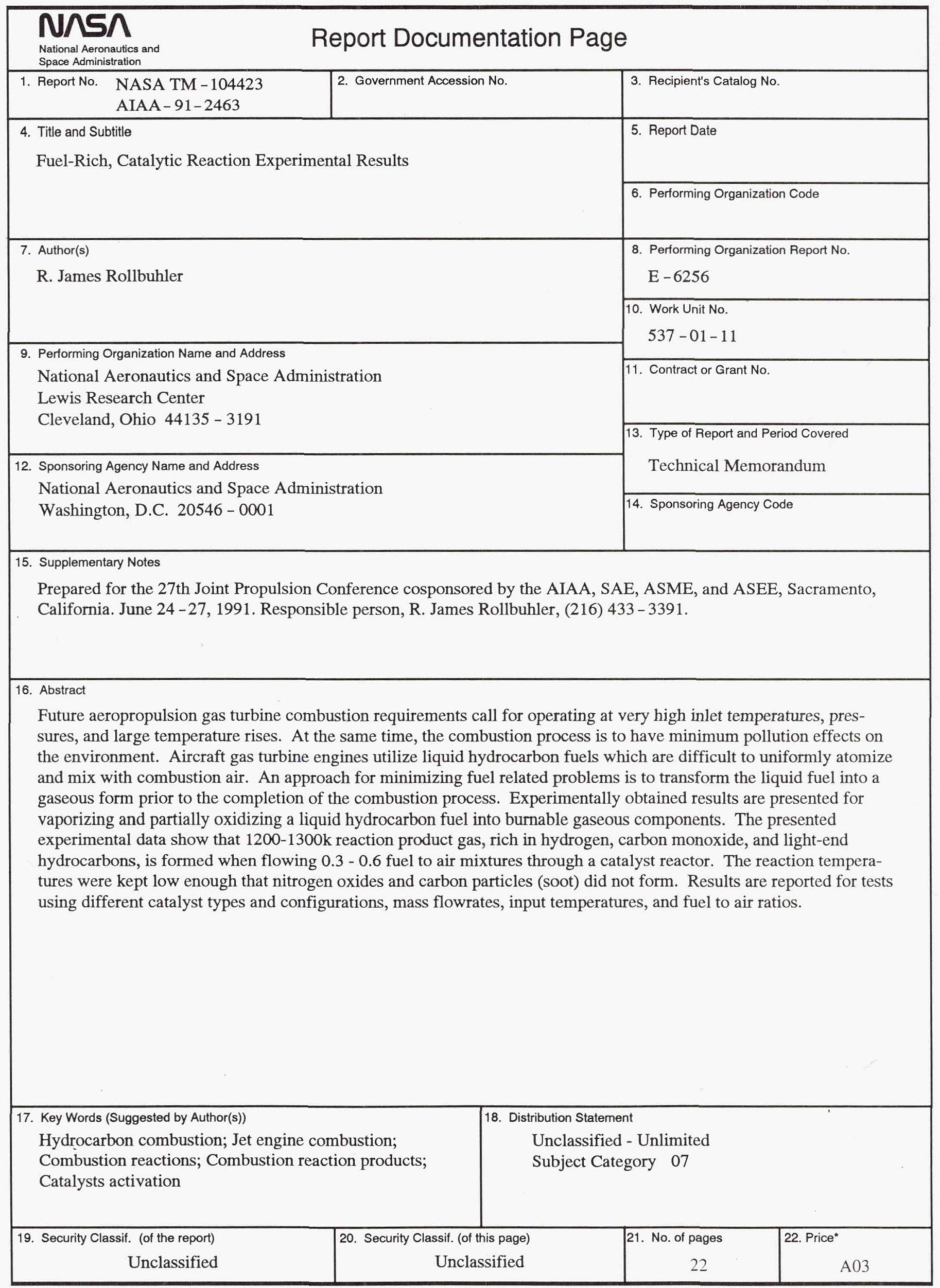


National Aeronautics and

Space Administration

Lewis Research Center

Cleveland, Ohio 44135

Official Business

Penalty for Private Use $\$ 300$ 